\title{
Cooperative Division of Cognitive Labour: The Social Epistemology of Photosynthesis Research
}

\author{
Kärin Nickelsen ${ }^{1}$
}

Accepted: 8 December 2020 / Published online: 19 March 2021

(C) The Author(s) 2021

\begin{abstract}
How do scientists generate knowledge in groups, and how have they done so in the past? How do epistemically motivated social interactions influence or even drive this process? These questions speak to core interests of both history and philosophy of science. Idealised models and formal arguments have been suggested to illuminate the social epistemology of science, but their conclusions are not directly applicable to scientific practice. This paper uses one of these models as a lens and historiographical tool in the examination of actual scientific collectives. It centres on the analysis of two episodes from the history of photosynthesis research of the late nineteenth- to mid-twentieth centuries, which display a wide and coordinated intellectual diversity similar to Kitcher's "division of cognitive labour" (1990). The concept, I argue, captures important aspects of the photosynthesis research communities, but the underlying process unfolded in ways that differ from the model's assumption in interesting ways. The paper unravels how the self-organised interplay of cooperation and competition, and the dynamics of individual and collective goals within scientific communities were influential factors in the generation of knowledge. From there, some thoughts are developed on how historical and philosophical approaches in the analysis of science can productively interact.
\end{abstract}

Keywords Social epistemology of science $\cdot$ History and philosophy of science $\cdot$ Division of cognitive labour · History of photosynthesis research

\section{Introduction}

Science is a collective enterprise: this has long been acknowledged, and most people agree that traditional epistemologies, which focus on the individual alone, are unable to capture the dynamics fully. The development of more adequate concepts and approaches, however, is still a matter of debate. How can we describe the generation of knowledge in scientific collectives, and how do social interactions and the interplay of personal and impersonal epistemic goals influence or even drive this process? These questions speak to core

Kärin Nickelsen

K.Nickelsen@1mu.de

1 History of Science, Ludwig Maximilians University, Geschwister-Scholl-Platz 1, D-80539 Munich, Germany 
interests of both history and philosophy of science and should be part of a broadly conceived social epistemology ${ }^{1}$ of science.

Philosophy of science has addressed the subject from various angles, including the question of how a scientific collective-and its members - can be said to "know" something at all (e.g. Andersen and Wagenknecht 2013; Bird 2014; Wray 2002). Another line of research investigates the impact and importance of collaborative or competitive attitudes among scientific actors. One of the more popular approaches to this end is the formal modelling of idealised situations and a normative assessment of their outcome (for a recent collection, see Boyer-Kassem et al. 2017). However, given the abstract nature of these models, it is often unclear, how their conclusions might contribute to the illumination of scientific practice. History of science, on the other hand, has likewise described how scientific communities were engaged in controversy, competition or collaboration; but most of these studies have largely ignored philosophical work in this area.

This paper tries to bridge the gap by using one of the philosophical models as a lens and historiographical tool in order to examine the dynamics of actual scientific collectives. The paper, thus, is written in the sense of a "philosophical history of science" (Arabatzis 2017), which uses concepts from philosophy of science in order to enlighten and better understand the course of historical episodes. It centres on the analysis of two examples from the history of photosynthesis research of the late nineteenth- to mid-twentieth centuries, which display a wide and coordinated intellectual diversity along the lines of a "division of cognitive labour" (Kitcher 1990). This concept, I will argue, captures an important aspect of the photosynthesis research communities, while the process unfolded in ways that differ from the model in ways that are both interesting and relevant. The paper unravels how the self-organised interplay of cooperation and competition as well as individual and collective goals within a scientific community proved conducive to the generation of knowledge. In effect, the paper demonstrates again, I hope, that there is benefit for history of science by taking on board the conceptual tools of philosophy; while philosophy of science mayand perhaps should - feel prompted to elaborate and refine their tools in view of these and other examples.

\section{Scientific Communities and the History of Photosynthesis Research}

Today, photosynthesis is known as the process by which solar energy is converted into energy that can be used in biochemical reactions, notably the reduction of carbon dioxide to carbohydrates. It is fundamental to life on earth, and the way organisms accomplish this task has intrigued scientists for a long time (e.g. Myers 1974; Höxtermann 1992; Govindjee and Krogmann 2004; Nickelsen 2015). Organic chemists starting from around 1840 developed the first tentative models of the photosynthetic mechanism, in the sense of a chemical pathway; but only from the 1920s onwards noticeable progress was achieved, and it took until around 1960 that an elaborate model on a molecular level was established. This included a set of two light reactions in two different photochemical systems and,

\footnotetext{
1 One reviewer correctly pointed out that this term is being used in very different ways, ranging from formal, mathematical approaches to testimony and group justification to qualitative analyses of knowledgegenerating activities within the scientific community in general. This paper consciously uses the term in the latter sense, since I do think that the former, more specific use refers to only one part of what a "social epistemology of science" should cover.
} 
linked to these reactions, a light-independent, cyclic pathway of carbon reduction. Almost immediately, this model became widely accepted, and in the decades that followed work on extending and refining it dominated the field.

Yet, when we try to understand how the notion of two light reactions was discovered around 1960, and by whom, we are facing problems. Sometimes, the British biochemist Robin Hill is credited with having solved the mystery. In 1960, he published a celebrated paper together with a young scholar from his lab, Fay Bendall: "The Function of the two cytochrome components in chloroplasts: A working hypothesis" (Hill and Bendall 1960). The paper suggested how, from the point of view of thermodynamics, an electron transport chain in photosynthesis that included two light reactions might work; and in some surveys, it is cited as the origin of today's scheme.

However, other scientists have been credited with the same thing-for example, the American general physiologist Robert Emerson, who in 1957 found the "Enhancement Effect" in photosynthesis. When Emerson illuminated algae cells with two light beams of different wavelengths, the photosynthesis rate increased disproportionally, which indicated that two different light reactions were driving the process (Emerson et al. 1957; Emerson and Chalmers 1958). Slightly later, in 1960, Emerson's friend and colleague, Eugene Rabinowitch, together with Govindjee, a PhD student from the lab, found two different pigment systems in algae cells, which pointed to the existence of two different light reactions (Govindjee and Rabinowitch 1960; Rabinowitch and Govindjee 1961). Independently, the Dutch biophysicist Bessel Kok found that one of the pigments in cyanobacteria reacted antagonistically to light of different wavelengths, which he explained by assuming that there were two different light reactions (Kok 1957; 1959; Kok and Hoch 1961). Finally, there was important work done in the groups of Louis N. M. Duysens in Leiden and Horst Tobias Witt in Berlin. In both places, sophisticated spectroscopic techniques were developed, and both observed, around 1960, evidence of two light-induced redox reactions in photosynthesis situated in two different photosystems (e.g. Duysens et al. 1961; Duysens and Amesz 1962; Witt 1960; Witt et al. 1961a, b). Speaking of Hill as the discoverer of the two light reaction scheme in photosynthesis is therefore only partially accurate, at best (see also e.g. Govindjee et al. 2017).

The collective nature of this discovery process is a recurrent pattern in the history of photosynthesis research. There were many protagonists, but no grand and towering figure; there were many productive lines of research, but not the one decisive experiment. It seems that either nobody discovered how photosynthesis worked, or everybody. ${ }^{2}$ An adequate description of this type of scientific research therefore requires a focus on the group and its interactions, in the sense of a "social epistemology of science", broadly conceived, which goes beyond the individual and helps us better understand how scientific communities generate knowledge and attain their epistemic goals.

Philosophers of science have become interested in social aspects of epistemology since the 1990s, at the latest, and the number of contributions to this field has constantly increased (for a recent overview, see Goldman and O'Connor 2019). Within this literature, general questions about the role of trust and testimony have received a lot of interest; and the development of formal, mathematical models with a normative perspective

\footnotetext{
${ }^{2}$ See, e.g., Arabatzis (1996; 2005), for an insightful discussion of the complicated nature of scientific "discoveries". Arabatzis mostly focuses on the discovery of theoretical entities, such as the electron, which is difficult enough; speaking of the "discovery" of entire processes, such as the system of light reactions in photosynthesis, is of course even more problematic.
} 
has taken centre stage (see e.g. recently: Boyer-Kassem et al. 2017). One of the landmark papers, which became the starting point of a lively debate, was Philipp Kitcher (1990) and his notion of "division of cognitive labour" in scientific communities (see for an overview, Muldoon 2013). In this essay, Kitcher attempted to explain how coordinated diversity emerges in scientific communities, and why it prevails. In the following, I will briefly sketch the principal idea and (even more briefly) its reception within philosophy; and then turn to my historical episodes and examine how the model can be used to better understand some of the practices and action patterns in science.

\section{The Division of Cognitive Labour}

Kitcher starts from the claim that, under some circumstances, cognitive diversity in a scientific community is good, because it prevents the community from settling too early on potentially false solutions. ${ }^{3}$ Yet, this diversity may be hard to maintain, because of a conflict between individual and collective "rationalities" and "interests" in science, originally identified by Kuhn (1977). Kitcher relates these rationalities and interests to the "personal" and "impersonal" epistemic goals that he assumes all members of the community pursue. If, for example, two methods are available to address a problem, and method ${ }_{1}$ has a higher chance of success, it seems obvious that everybody will use method ${ }_{1}$. It is in the scientist's individual interest to use the most promising approach, and their personal goal to solve the problem themselves. It is in the community's interest, however, to maintain diversity, a "division of cognitive labour"- the community should "hedge its bets", as Kitcher calls it, in order to attain its members' impersonal goals: a solution of relevant problems, no matter by whom.

This seems to require the existence of a special type of "altruistically rational agents" in science, as Kitcher put it, "who are prepared to pursue theories that they regard as inferior when, by doing so, they will promote achievement of the goals of their own (and their colleagues') impersonal epistemic intentions." This "raises an even more bloodless ideal of scientific rationality than that criticised by historians and sociologists of science" (Kitcher 1990, 9, fn. 5). The apparent problem is resolved, Kitcher argues, if we consider that scientists are not only striving for knowledge but also for social reward; and he assumes the potential reward for each scientist to be inversely proportional to the number of people

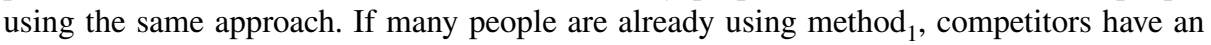
incentive to use the less promising $\operatorname{method}_{2}$. The chances of success may be lower; but if the method succeeds, the reward will be so much higher. This, Kitcher argues, is how the reward system in science actually works. So, here is an explanation for the existing, and desirable, division of cognitive labour in scientific communities. It is produced by the scientists' "thirst for fame and fortune" (Kitcher 1990, 16). ${ }^{4}$

\footnotetext{
${ }^{3}$ Other philosophers at the time shared these concerns. Solomon $(1994,339)$ even postulated "consensus is not normatively appropriate unless theories show clear and substantial differences in degree of empirical success."

4 Kitcher extends this argument to the problem of theory choice, and although he found this more difficult to analyse he still found corroboration of the general claim that "psychological factors (and scientific institutions that exploit those factors) often thought to be detrimental to cognitive progress might turn out to play a constructive role" $(1990,22)$.
} 
This is an attractive approach with a counter-intuitive punch line. It is, however, based on some very specific assumptions: first, the model assumes a community that pursues one clearly defined epistemic goal; second, it deals with rational agents who are able and willing to choose their approaches strategically from a range of equally available options. Third, it assumes a zero-sum distribution of social reward within a community: if one scientist gets a large portion of it, there remains less to be shared by others. None of this is implausible in principle, but it surely is not a standard constellation in science.

In contrast to the qualitative account that I have given here, Kitcher himself translated his idea into a formal algebra, which he developed further in Kitcher (1993), and which was widely received in the literature. Michael Strevens (2003), for example, picked up the observation that individual non-epistemic motives can improve the overall epistemic outcome, and modelled the effect of different reward systems in science. In line with Kitcher, Strevens concludes that the priority rule ensures a productive division of labour, and this he takes to explain both its origin and its continued existence. Michael Weisberg and Ryan Muldoon (2009) developed hypothetical epistemic landscapes, and investigated the effects of three research strategies: controllers, followers, and mavericks. The most successful community, Weisberg and Muldoon conclude from their models, consists of a mixture of mavericks and followers, where mavericks break new ground, and followers clear up the details.

All of these examples, which are taken from a growing body of literature in this field, focus on formal, mathematical problem statements and solutions. They analyse hypothetical scenarios with little or no empirical grounding and derive normative conclusions. They raise interesting questions and offer impressive responses; but owing to their lack of engagement with examples, their insights are of doubtful relevance to the analysis of scientific practice. Mavericks may be important figures in an imaginary community; but how do they fare in real life? Will they ever get their work published? Do we find that scientists change and adapt their strategies in the face of new circumstances, and should this perhaps be integrated into the model? There is a lot to be learned from this body of literature; but there is also a need to bring them into dialogue with the study of actual science, past or present.

Kitcher (1990) illustrates this problem. One of the (few) examples that he uses is a search for the structure of a "very important molecule" (VIM), which could either be achieved by using sophisticated crystallography or, alternatively, by simple toy tinkering. In Kitcher's imaginary scenario, all the rational scientists used crystallography, that is, the most promising approach, and since this was not leading them anywhere, they were still working on it in 1990. The implication seems to be that some of them should have taken the irrational route and tinkered with toys, as real scientists so ingeniously did. In the paper, this is merely referred to anecdotally, as a hypothetical, illustrative example without argumentative weight. Still, if we look at the episode on which this scenario is implicitly based, the process was very different. James Watson and Francis Crick did not choose toy tinkering in a conscious maverick move; rather, crystallography required skills and expertise that neither of them had. Moreover, also their model was ultimately based on crystallography data, which they had stolen from Rosalind Franklin. The story is, hence, a slightly doubtful illustration of Kitcher's point: that it may pay off to take the less promising approach.

In the following sections, I will try to use the notion of a "division of cognitive labour" for an analysis of episodes from the history of science. (And I readily admit that I am thereby entering territory that Kitcher, Muldoon, and others had never intended to cover.) It turns out that in the nineteenth- and twentieth-century photosynthesis communities a 
"division of cognitive labour" of sorts can be observed, albeit in a manner that differs in interesting ways from the idealised model.

\section{Photosynthesis Research Around 1900}

"If we try to nail down the present state of our scientific views on the assimilation of carbon in the chlorophyllous parts of plants, we are forced to confess that [...] in this fundamental question of plant physiology we are still at the stage of discussing the possible and the probable." This is how the German plant physiologist Johannes Reinke characterised the state of photosynthesis research in the second half of the nineteenth century (Reinke 1882, 289). The body of knowledge concerning organic reactions in the living organism was scant and the methods available went hardly beyond input-output measurements. As late as 1925 the British plant physiologist Walter Stiles maintained, "the nature of the intermediate substance or substances formed in photosynthesis is a subject on which [...] our real knowledge is practically negligible" (Stiles 1925, 193). The few things that everybody agreed on are succinctly summarised in the following definition from an encyclopaedia for the German educated middle class of 1907 :

Assimilation in the botanical sense of the word is the formation of carbohydrates from carbonic acid and water while oxygen is released. This process is limited to the chlorophyllous assimilation system (assimilation tissue) and requires the involvement of sunlight. (Anonymous 1907, 890)

This brief statement can be conceived of as an elementary input-output model of the process (Fig. 1). The starting materials were carbon dioxide and water, the products were carbohydrates $\left[\mathrm{CH}_{2} \mathrm{O}\right]_{\mathrm{n}}$ and oxygen $\left[\mathrm{O}_{2}\right]$. Important factors on the way from one to the other included the influence of light and the green pigment chlorophyll [Chl]; and since photosynthesis stopped as soon as the cell was damaged, the "living cell", or some aspect of it, also seemed to be important. But how these elements interacted, and which intermediate steps and, presumably, compounds were involved, was very unclear.

From the point of view of chemistry, two key questions had to be answered in this context: (1) How was carbon dioxide, a highly stable compound, chemically reduced in plants? (2) How were the one-carbon units that (presumably) resulted from the carbon dioxide reduction joined together to form large molecules such as sugars? Two main answers to these questions emerged in the second half of the nineteenth century, and the first came from the German chemist Justus von Liebig (1843). Starting from the observation that fruits gradually sweeten as they ripen, Liebig surmised that, as a first step in photosynthesis, carbon dioxide was turned into oxalic acid. And oxalic acid would then stepwise be reduced to tartaric, malic or citric acid, from which eventually (and somehow) carbohydrates were formed. Oxygen, presumably, was released on the way-while Liebig had a comparatively clear idea of how to answer the first question about the reduction process,

Fig. 1. An elementary input-output model of photosynthesis: the basic consensus from the midnineteenth until the beginning of the twentieth century.

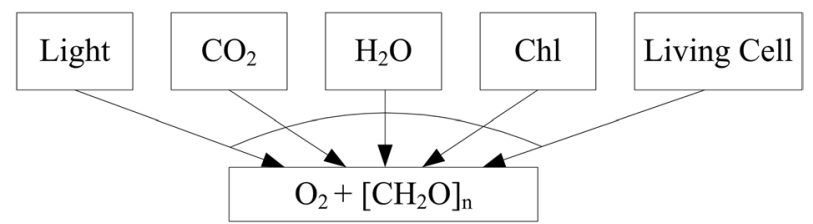


he was very vague in responding to the second. This was called out by Adolf von Baeyer (1870), another German chemist. Baeyer contested the notion of a stepwise reduction process, and rather suggested that the first step of photosynthesis was the binding of carbon dioxide molecules to the chlorophyll. In this state and under the influence of light, the carbon dioxide was (somehow) reduced in one large step down to formaldehyde, upon which oxygen escaped. In subsequent condensation reactions-a class of chemical reactions that Baeyer had helped to elucidate-the formaldehyde would then produce carbohydrates.

Neither Liebig nor Baeyer had empirical evidence of the process taken from plant cells. Both started from observations in-vitro and transferred them to photosynthesis by analogy. It was acknowledged that these inferences were not necessarily reliable; but since nothing better was available at the time, the approach was not only accepted, but also emulated by their chemical colleagues. In fact, over the following decades, the number of models of the photosynthesis pathway multiplied. ${ }^{5}$ Within the limits of this essay, I will only mention four additional proposals brought forward by other German chemists at the time: Emil Erlenmeyer, Erwin Baur, Georg Bredig and Richard Willstätter in collaboration with Arthur Stoll. The chemical details are unimportant for this essay's focus, but the main functional components-or "modules", as one may call them-are given in Fig. 2 (for the papers, see Erlenmeyer 1877; Baur 1913; Bredig 1914a, b; 1915; Willstätter and Stoll 1918).

These models diverge, but they were not completely disparate. Rather, some of the "modules" reappeared in different combinations, such as the "formation of a chlorophyllcarbon dioxide complex", or the "reducing of carbon dioxide via organic acids". Perhaps the most striking case is the "formation of carbohydrates from formaldehyde": this module, which explained the polymerisation process, was integrated into all later models despite the fact that formaldehyde was a cell poison and never detected in plant cells (Graßhoff and Nickelsen 2011). Similarly widespread became the assumption, first formulated by Erlenmeyer, that a formic acid derivative and some peroxidic compounds were involved in the process, the decomposition of which gave rise to the photosynthetic oxygen. Willstätter and Stoll, for example, ingeniously recombined it with the chlorophyll complex and the formaldehyde modules, added some hypotheses from their own field of expertise, notably the enzyme hypothesis, and thus presented a completely new amalgamation of ideas, some of which had been around for decades.

Thus, by 1918, we have a wide range of options covered within the field. As we see from the scheme, modules were picked up from earlier suggestions, refined, and complemented with something new. In effect, the situation was close to what Kitcher and others described as the desirable status quo: a pluralism that, in line with everybody's impersonal epistemic goals, increased the chances of the community to hit on something useful. Keeping as many models as possible under discussion, that is, maintaining a broad division of cognitive labour, was a well-founded strategy if one regarded the model-building process as a cooperative enterprise of the whole group. At the same time, it was also a reasonable strategy for individual actors, although nobody deliberately chose an inferior approach in search of higher reward. At the time, it was impossible to determine whether carbon dioxide was reduced through a series of organic acids, or was converted into formaldehyde. The chemists were working in a situation of high epistemic uncertainty, so that any suggestion, even an outsider proposal, might prove, in the course of time, to be the better horse to bet

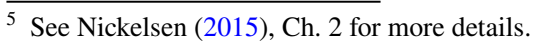




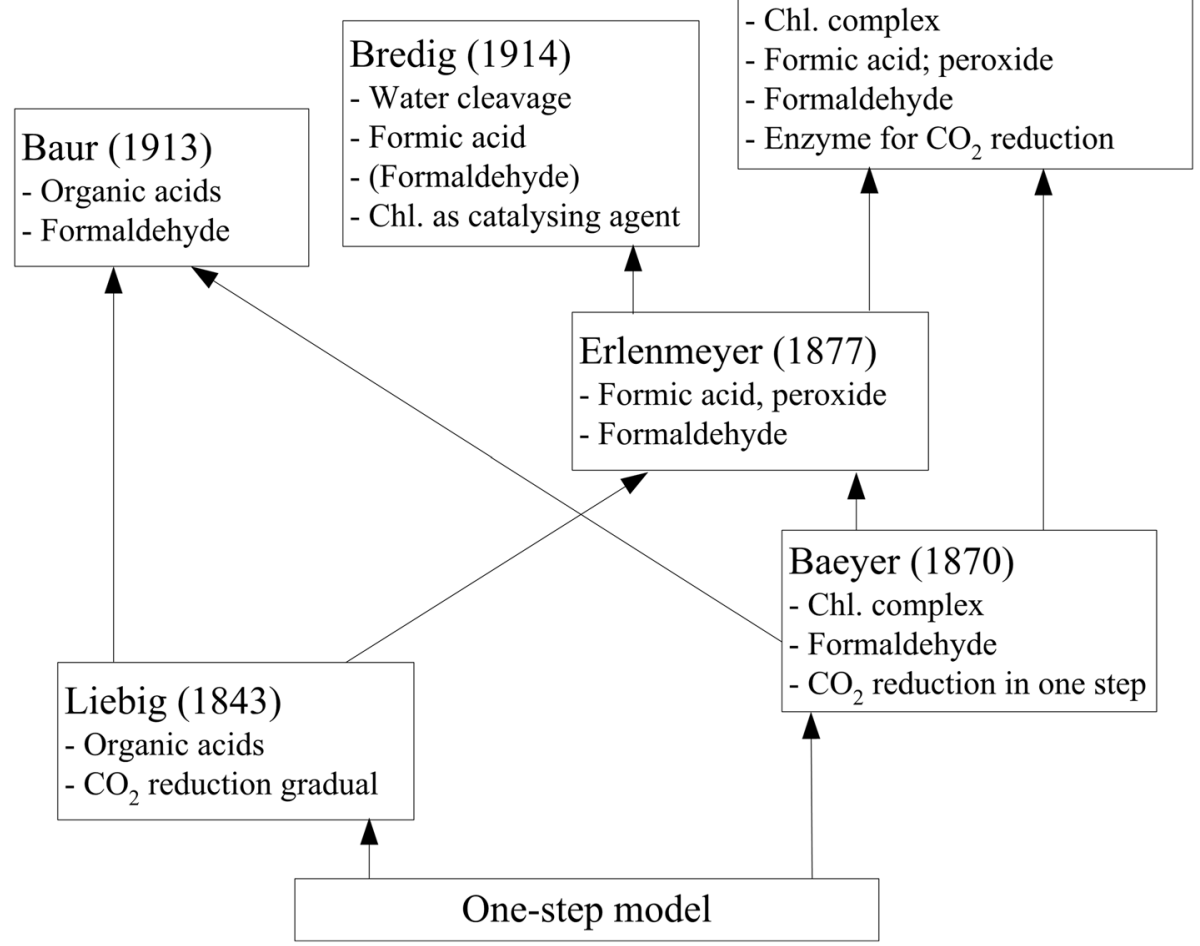

Fig. 2. Photosynthesis models in the decades around 1900 and their "modules". The arrows from denote the relationship "modules of model $\mathrm{x}$ were integrated into model y".

on. (Today, we know that the water cleavage hypothesis, brought forward by Bredig and ignored by almost everybody else, was exactly of this kind).

But it would be wrong to think of these chemists as collaborators in any more literal sense, or, alternatively, competitors in a race to solve photosynthesis. In fact, none of the chemists was specifically interested in photosynthesis as such, or studied it for an extended period at depth and detail. They turned to the issue only in passing and made a limited contribution, such as one, or very few, rather short papers, and then moved on to other concerns - or, more precisely, returned to their original, main, research goals (see Fig. 3). Baeyer, for example, was studying condensation reactions, including the reactions of formaldehyde. The formaldehyde model of photosynthesis appeared in his paper to illustrate one of the types of condensation reactions that Baeyer investigated. This explains, why, even though the formaldehyde question became the subject of protracted discussion, Baeyer himself never returned to the issue: he was not particularly invested. Erlenmeyer was working on the structural elucidation of organic molecules as well as the chemical properties of double and triple bonds - and he turned to photosynthesis on the way. Baur published a series of papers on the topic of photolysis, including the photolysis of formaldehyde; and this led him to think about photosynthesis. Bredig, meanwhile, was interested in the effects of surface catalysts, such as palladium or platinum, and in the chemistry of formic acid. $\mathrm{He}$ 


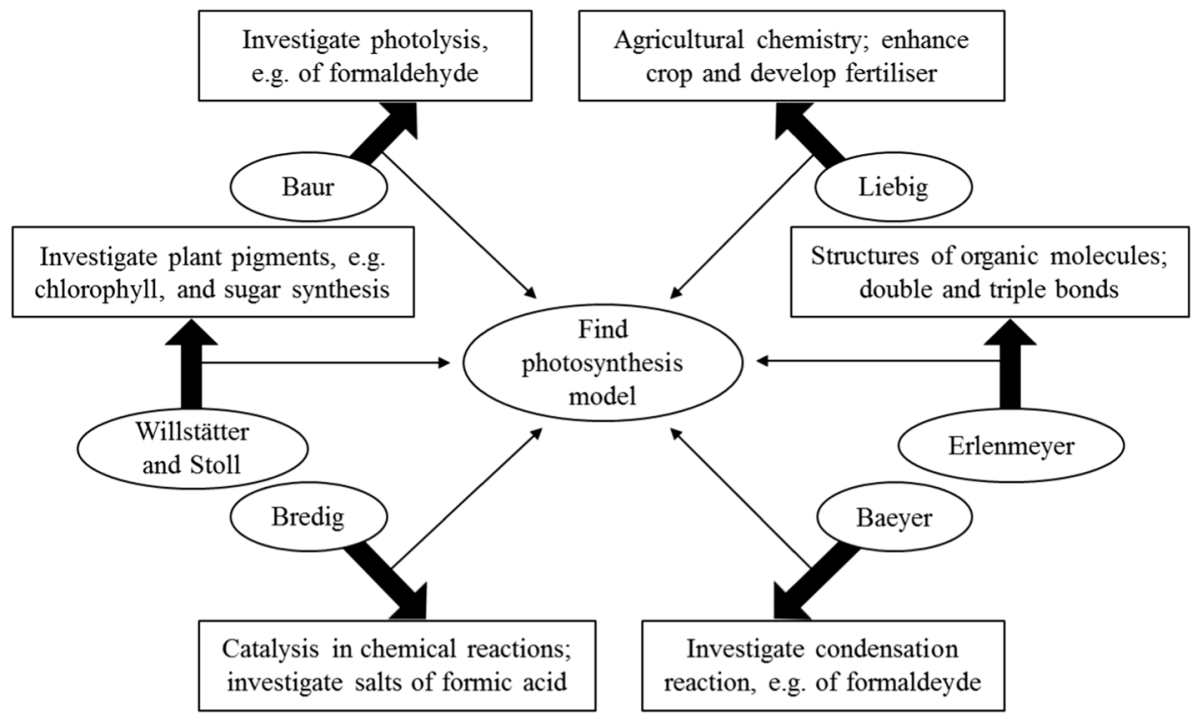

Fig. 3. The scientists and their individual research goals. Arrows in bold indicate the relationship "X pursues the superordinate goal Y". The thin arrows indicate that, in the course of pursuing their goals, each of these chemists temporarily decided to briefly turn to "finding the model of photosynthesis" as an incidental goal in passing (or, in the case of Liebig as well as Willstätter and Stoll, a sub-goal).

surmised that also chlorophyll acted as a surface catalyst and might reduce carbonates to formates in photosynthesis.

Willstätter and Stoll, finally, had been working on the chemistry of plant pigments, in particular chlorophyll, for more than ten years. ${ }^{6}$ Yet, even then, "finding the photosynthesis model" was not their first and primary goal, as they made clear:

Even though our experiments may contribute to describing more precisely the processes of [carbon dioxide] assimilation, at the same time they clearly give a negative answer to the question as to whether it is already possible to realise this assimilation outside the living cell. It is too early for experiments of artificial assimilation under the influence of chlorophyll. This is not really a negative conclusion, it is a positive finding that ought to inspire and point the way to new work. (Willstätter and Stoll 1918, preface, III-IV.)

As we can take from this paragraph, Willstätter and Stoll originally wanted to realise artificial photosynthesis: implement the reduction of carbon dioxide to carbohydrates in a light-driven reaction independent of the plant cell. It was only in order to reach this goal that Willstätter and Stoll attempted to clarify how the process operated in plants.

It is clear from these examples that the chemists did not strategically choose their approaches to solve the mystery of photosynthesis. They rather chose to contribute to photosynthesis because they could do so with the approaches they had-as a spin-off (or byproduct) of their work on other projects. This intellectual opportunism is similar to, but

\footnotetext{
${ }^{6}$ They had, e.g., already established that magnesium was an integral part of chlorophyll and had been the first to find a practicable method for isolating chlorophyll from plants; cf. Willstätter and Stoll (1913).
} 
still different from the opportunism of research that was discussed e.g. in Knorr-Cetina (1981, esp. 33-36). In her ethnographic work, Knorr-Cetina observed that scientists often chose projects that exploited local resources, such as specific laboratory facilities; preferred analytic methods that were convenient to organise; and created alternative (and sometimes highly successful) ad-hoc solutions, if some equipment was unavailable. Knorr-Cetina also found that ideas were sometimes described as the contingent result of occasions that scientists "ran into". In the photosynthesis case, the opportunism is more on the level of epistemic goals. The scientists jumped on the opportunity to use their skills and knowledge to resolving an important research problem, in this case the functioning of photosynthesis in green plants, without investing too much.

One may ask why they remained so uncommitted. The answer seems to be pragmatic. Photosynthesis clearly was an important research problem, but it was also an extremely complicated one. Building a career on its (bio)chemical investigation was not yet an option at the time, but it was attractive to make a pass. Each individual scientist only spent minimal time and effort on the issue with the prospect of potential reward, while, at the same time, they all contributed to the attainment of the impersonal goal of the community (namely, explaining how photosynthesis worked). In effect, a wide range of possibilities was developed and constantly refined, for subsequent generations to build on-it resulted, in other words, in a neat division of cognitive labour.

There is a number of other interesting aspects to this episode - there is, for example, a pattern of theory change to consider, in the form of a genealogy of modules (see Fig. 2). One could also examine the chemists' analogical inferences, a very popular (and not trivial) methodology at the time. But these are leads to pursue elsewhere; instead, I will turn to the mid-twentieth century and examine photosynthesis research at a more advanced state of the field.

\section{Photosynthesis Research in the 1930s-1950s}

By the mid-twentieth century, a considerable body of empirical data on different aspects of photosynthesis was available, mostly gathered from algae cells, and scientists from various fields tried hard to make sense of them (on the use of Chlorella green algae as model organism in photosynthesis, see Zallen 1993; Nickelsen 2017). In fact, photosynthesis research had emerged as a field with a stable cast of characters: a community, which pursued a shared epistemic goal-find the mechanism of how carbon dioxide is turned into carbohydrates in photosynthesis. But within these confines, the community was highly diverse. This is reflected, for example, in one of the first edited volumes on the topic, published in 1949 by the physicist James Franck and the plant physiologist Walter Loomis (Franck and Loomis 1949). The twenty-two essays collected therein addressed biochemical, biophysical, cell physiological, microbiological, and photochemical questions, and reported the use of a wide range of methods, such as manometry, electron microscopy, spectroscopy of various kinds, etc. The essays were nevertheless linked through mutual references, and cited other publications by central figures in the field, even if they were published in journals from other disciplines.

Since the aim of this paper is to examine how a community's social and epistemic goals, choices, and motivations influence the generation of knowledge, let me introduce at least three exemplary protagonists, how they came to work on the topic, and how their efforts contributed to the resulting ensemble. There was, for example, the biochemist Robert 
("Robin") Hill, who was already mentioned in the introduction (see also Bendall 1994). During the 1920s, Hill worked in the Cambridge-based Institute for General Biochemistry on the reversible oxygenation of haemoglobin, the blood pigment, and on the role of cytochromes in respiration. Hill closely collaborated on this subject with David Keilin, who then established the existence of a respiratory electron transport chain that included cytochromes as vital components (Keilin 1966; for their collaborative work: e.g. Keilin and Hill 1933; on the institute: Kohler 1982). In the late 1930s, Hill slightly adapted his concepts and methods, and then started to investigate the role of pigments and cytochromes in photosynthesis. Eventually, he suggested a photosynthetic electron transport chain, analogous to the one that Keilin had found in respiration, which included specific cytochromes and was driven by two light-induced reactions (Hill and F. Bendall 1960).

Another prominent figure was Robert Emerson, a Harvard-trained general physiologist, who also started his research career with topics in respiration before he turned to photosynthesis. Emerson became proficient in biophysical manometric techniques in the investigation of Chlorella, a genus of unicellular green algae. He studied in detail the energy budget of the process, also known as its maximum quantum yield (Nickelsen and Govindjee 2011; Nickelsen 2016). And when Emerson explored the effects of different wavelengths in this context, he found the "Enhancement Effect", which was mentioned earlier in the introduction, and which became a crucial piece of evidence for the two-light reactions scheme (Emerson et al. 1957; Emerson and Chalmers 1958).

And there was James Franck, who in 1925 received the Nobel prize for his work in nuclear physics. Yet, when Franck emigrated from Nazi Germany in 1933, first to Copenhagen, then to the United States, he returned to his earlier interest in photochemistry and in this context came across the photosynthetic pigment chlorophyll (Lemmerich 2007). Franck was surprised to learn how little was known about the pigment and the process in general, and decided that the field needed a physicist to resolve the issue. (After all, photosynthesis was one of the few processes in nature that involved photochemical reactions, one of his key fields of interest.) Over the next decades, Franck published various theories, which attempted to clarify the process from a quantum physical point of view, but none of these was particularly successful (e.g. Franck and Herzfeld 1937; 1941; Franck 1949; 1951; 1958; Franck and Rosenberg 1964).

This limited set of protagonists illustrates a widespread pattern: even the central figures came to photosynthesis on highly individual "investigative pathways", to borrow the term coined by Frederic L. Holmes (2004). This had important consequences for the composition and orientation of the field. Hill, Franck and others turned to photosynthesis for contingent reasons, and they concerned themselves only with select aspects of the process. In fact, they studied in photosynthesis the same issues that they had studied before: redox reactions of pigments, metabolism of green algae, or the physical foundations of photochemistry. They did not choose their approaches in order to solve photosynthesis. Rather, they chose to work on photosynthesis, first, because it was an interesting problem; and, second, because one aspect seemed accessible to them, given their respective knowledge and skills. The latter then naturally defined the scientists' personal sub-project within the field. Clearly, they had to adapt their approaches, sometimes quite substantially-Hill, for example, had to get used to working with plant mesh instead of blood. However, the conservative element in their studies is striking (for more details, see Nickelsen 2019).

From these individual pathways and decisions, photosynthesis research emerged as a field with great internal diversity, while the resulting intellectual landscape was surprisingly well organised, in a broad "division of cognitive labour" that covered many of the central areas of study. Figure 4 provides a rough (and certainly incomplete) overview: of 


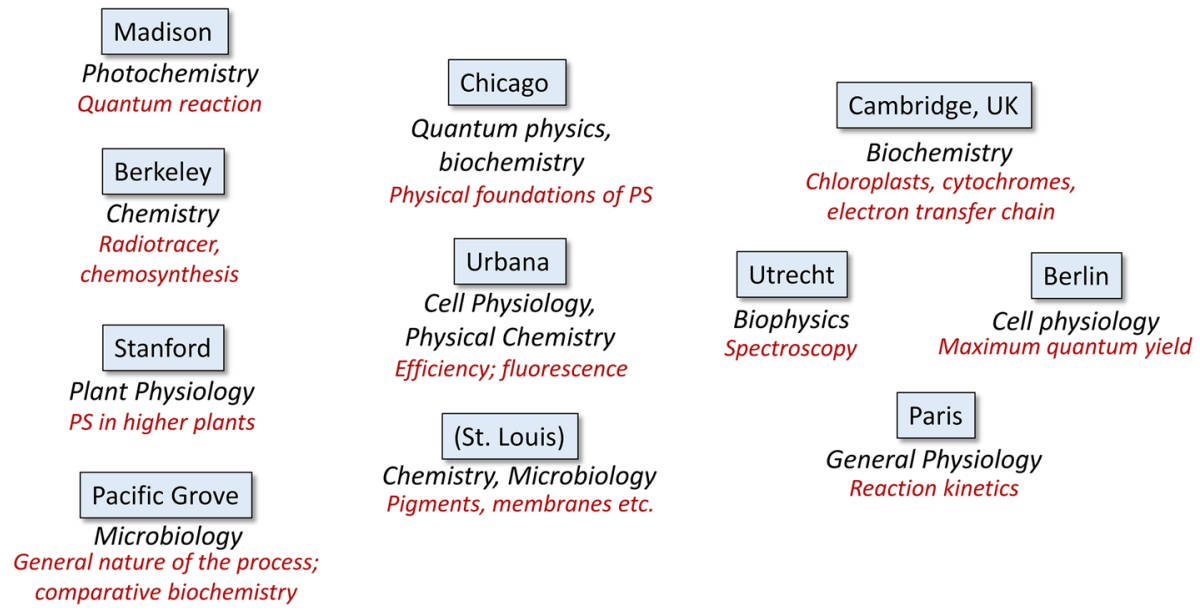

Fig. 4. A rough (and incomplete) overview of the places where photosynthesis was studied during the 1950s; the disciplines, to which this research was affiliated; and a simplified description of the main points of interest.

places, where photosynthesis was investigated in the 1950s; of disciplines, to which this research was affiliated; and a simplified label of the respective topic of research. The shared, overarching goal of the community was to find a model of the photosynthesis mechanism. However, since this in itself was not attainable to any one scientist, the individual groups defined sub-goals according to their background and expertise: in Chicago, where Franck had his laboratory, the physical foundations were investigated; in UrbanaChampaign, where Emerson worked, the process's efficiency; in Cambridge, Hill turned to the redox reactions of pigments, and so forth. These sub-goals were challenging, but sufficiently realistic; and their attainment would mean both an individual success and an important step towards reaching the overarching goal.

A large laboratory may have designed its personnel along similarly diverse and interdisciplinary lines; but there was no central authority here. The scientists created their own professional niches, and thereby determined the composition and intellectual orientation of the group. This self-organised, bottom-up process only comes into view by choosing a perspective that reaches beyond one or two individual actors. Taking the bird's eye view is often criticised in history of science, because we lose so many details and complexities; but the current example shows that there are also aspects that we would miss if we studied this development only from the perspective of individual players or institutions. If we want to understand how a group and its members attain both, personal and impersonal goals, we need to integrate this higher level as a complement to more in-depth analysis.

At the same time, it is only through in-depth, microhistorical studies that we discern the many links between the players. The scientists of this community were in constant exchange through formal and informal meetings as well as lengthy correspondences (many of which have survived). They negotiated important epistemic goals and methodological norms, and they shared their data and interpretations even before they were published. ${ }^{7}$

\footnotetext{
7 For more details, see Nickelsen (2015, Ch. 7). Most players were highly committed to practices of constructive exchange. At the same time, there was a fierce controversy between Emerson (and others) and the German cell physiologist Otto Warburg on the maximum quantum yield of photosynthesis. Very soon, the
} 
When around 1950 the community started to grow, the frequency of large conferences significantly increased, including regular meetings at Gatlinburg, Tennessee, in order to keep the conversation going (cf. Nickelsen 2019). One has to keep in mind, however, that even then, according to estimates at the time, there were no more than around one hundred photosynthesis researchers worldwide. Among physicists in particular, photosynthesis was regarded as "a completely impossible topic"; it was "too green, too strange and too complicated" to be taken seriously (Witt 1991, 58). This skepticism also explains why so many protagonists, although they identified as members of the photosynthesis community, also retained their disciplinary identity as microbiologist, biochemist etc., in terms of institutional affiliation, choice of journals, methodological standards, or key research questions. The scientists made sure that they not only addressed the other photosynthesis experts, but also their fellow chemists, physiologists, and microbiologists - the community hedged its bets, but the players also hedged theirs.

It is from this social and intellectual constellation that the two light reaction-scheme of photosynthesis emerged; and we are now in a much better position to understand its many places of origin. The research lines had been in place for some time already. They were pursued in institutional independence, but the protagonists were in regular exchange. At some point, around 1960, the theoretical arguments as well as the experimental data converged on the existence of two light reactions; and although the proposal was unexpected and unorthodox, it was almost immediately accepted. The fact that independent lines of research came to the same conclusion based on different methodologies made the claim much more persuasive than any of them would have been on their own. In other words, the fact that they had reached the finish hand in hand did not diminish the rewards for the individual scientists but increased them. The value of fostering diversity was acknowledged already at the time, for example, at a large conference on "Light and Life" of 1960, where many of the protagonists were present. The introductory speaker, Cornelis B. van Niel, a renowned microbiologist who had made important contributions to photosynthesis research, observed that scientists had "a habit of defending what they like to do as the best possible approach":

On the other hand, it has also been defended [...] that science is the search for unity [...]. While there is every reason to emphasize unity perhaps more, this is not a good justification for eliminating variety. (van Niel 1961, 315)

In photosynthesis studies, variety by then had clearly proven its value.

\section{Division of Cognitive Labour in Photosynthesis Research}

I started this essay from the observation that the history of photosynthesis research is the history of a field that had many protagonists but not the one leading figure and the one crucial experiment. An adequate understanding of how this community, and the individual scientists within, attained their epistemic goals, therefore requires a somewhat coarsegrained, middle-range perspective, where individuals and their goals and actions are still

Footnote 7 (continued)

latter was almost completely isolated, and fighting against Warburg's stubborn lack of compromise only strengthened the ties among other people in the field (see Nickelsen and Govindjee 2011). 
important, but equal weight is put on the network and the interrelations. One of the philosophical concepts developed to analyse such communities is Philipp Kitcher's (1990) idea of a "division of cognitive labour". When I used this concept as a lens and filter, comparable intellectual "divisions" became in fact discernible. In the case of the nineteenth-century chemists, a variety of models of the pathway emerged in the form of a recombination and refinement of explanatory modules. In the twentieth century episode, a variety of disciplinary and methodical approaches were used, each of which addressed specific aspects of photosynthesis, while the group fostered regular exchange in order to bring the perspectives together.

The phenomenon as such, it seems, is similar, but in both cases the processes differed from Kitcher's model assumption. First, not the methods, but the problems were chosen. Liebig, Baeyer and Erlenmeyer originally pursued other research questions, but at some point realised that with their conceptual tools they could also contribute, if only in passing, to the explanation of photosynthesis. Scientists often are not even in a position to select their approaches strategically. ${ }^{8}$ Franck may have wanted to work with algae cells instead of equations but the necessary techniques were unavailable to him. Instead, he contributed to photosynthesis research from his own disciplinary perspective; and the fact that he could use the skills and knowledge that he had, was the main reason, I claimed, that Franck, and so many others, came to work on photosynthesis in the first place-out of a research opportunism, of sorts. Second, the photosynthesis community was not stable and homogeneous in terms of personal and impersonal goals but heterogeneous, unstable, and in constant change. Especially in the twentieth century, the scientists did not find ready-made tasks to work on but instead built individual "research niches" for themselves. Before Hill had moved from respiration to photosynthesis studies, nobody had thought about investigating the role of pigments in the process and exploring the possibility of an electron transport chain. Hill and others defined sub-goals that they were able to pursue with their own expertise, while all of them were also committed to a shared goal: explaining photosynthesis. The resulting interaction of personal and impersonal goals shaped the photosynthesis community and its work during these years.

However, third, it was not a competitive race that unfolded, but a largely cooperative pattern of action. People generously shared data and interpretations, even before they were published, and constructively criticised each other-not because they were altruistic, but because the problem was so complicated that they needed each other's help. Emerson was excellent in handling manometry and Chlorella algae, but he depended on others, such as Franck, for a deeper understanding of the photochemical reactions. The resulting pattern of exchange and cooperation was conducive to the generation of knowledge within the community; but it also improved everybody's individual chances to succeed. Fourth, the resultant process of coordination and mutual adjustment also enabled the scientists to take part in the success of others. In the example of the two light reaction scheme, various independent groups of scientists reached the goal almost simultaneously, but not head to head but hand in hand. Their findings were complementary and corroborated each other, so that all of them were credited in a non-zero-sum distribution of reward (or, to put it differently, a distribution that granted everybody a large share, given that the result was so robust).

All of this diverges substantially from the (hypothetical) assumptions and (normative) conclusions of Kitcher's model. This is unsurprising, since this model, as well as others

${ }^{8}$ This was acknowledged from the start and dropped in subsequent models, such as Muldoon (2017). 
of its kind, never intended to be empirically adequate. It still proved useful as a conceptual tool in my "philosophical history" of photosynthesis research, and, on this measure, served its purpose. However, if these models were construed not only as the basis of formal arguments but as reflecting patterns of scientific practice, albeit on an abstract level, one might feel prompted to revisit them. One could, for example, define case distinctions of how intellectual division within a community plays out in different situations and what it refers to: techniques, conceptual approaches, etc. It might also be worthwhile to distinguish between patterns in different stages of a field's development. In the periods that I studied the search for the biochemical and biophysical mechanism of photosynthesis was still comparatively young. It is interesting to compare these episodes to Melinda Fagan's (2010) observation of a late twentieth-century scientific community in search of hematopoietic stem cells (HSC). Several independent groups participated and, like the photosynthesis community, carefully coordinated their efforts. Each group committed to a slightly different technique, shared their data with others, and discussed preliminary results at regular meetings. In contrast to the photosynthesis community, however, the target was clearly defined and the number of approaches limited. Soon enough, one particular institution, the Weissman Laboratory at Stanford, developed into a centre of stem cell research and became large enough to accommodate a wide diversity of projects and approaches, which, at least to a certain extent, were subject to central planning. All of this indicates a level of maturity and diversification, which photosynthesis research would only arrive at in the late 1960s. Maybe it is worth investigating these changes over time in more detail and integrate them into philosophical models.

Hasok Chang (2011) once suggested that instead of thinking about philosophy as "general" and history as "particular", and then try to draw inferences from one to the other, we rather should think of philosophical concepts as "abstract" and historical episodes as "concrete", where neither is primary but both illuminate each other. In this sense, one could use the (inevitable) differences between models and examples as starting points to reassess and refine existing model suggestions, then examine yet other examples and see whether or not they fit the scheme. And from this back and forth, which is at the core of an integrated History and Philosophy of Science, we would probably learn a lot about patterns of intellectual diversity and social interactions and their effects on the generation of scientific knowledge in groups.

Acknowledgements The paper is based on a talk at the Third International Conference of the German Society for Philosophy of Science (February 2019, Cologne/Germany), and I am grateful to Andreas Hüttemann and the other organisers who invited me to speak at this occasion. A different version of the talk was presented in November 2019 to the HPS Department at Cambridge, UK. The paper greatly benefited from comments and questions that I received at both occasions as well as from Caterina Schürch and Raphael Scholl, who read earlier versions of the paper, and from the highly valuable feedback from two anonymous reviewers.

Funding Open Access funding enabled and organized by Projekt DEAL.

Open Access This article is licensed under a Creative Commons Attribution 4.0 International License, which permits use, sharing, adaptation, distribution and reproduction in any medium or format, as long as you give appropriate credit to the original author(s) and the source, provide a link to the Creative Commons licence, and indicate if changes were made. The images or other third party material in this article are included in the article's Creative Commons licence, unless indicated otherwise in a credit line to the material. If material is not included in the article's Creative Commons licence and your intended use is not permitted by statutory regulation or exceeds the permitted use, you will need to obtain permission directly from the copyright holder. To view a copy of this licence, visit http://creativecommons.org/licenses/by/4.0/. 


\section{References}

Andersen, H., \& Wagenknecht, S. (2013). Epistemic dependence in interdisciplinary groups. Synthese, 190(11), 1881-1898.

Anonymous. (1907). Assimilation. In: Meyers Grosses Konversationslexikon (Vol. 1, 6th. ed.; pp. 890-890). Leipzig: Bibliographisches Institut.

Arabatzis, T. (1996). Rethinking the "discovery" of the electron. Studies in History and Philosophy of Modern Physics, 27, 405-435.

Arabatzis, T. (2005). Representing electrons: A biographical approach to theoretical entities. Chicago: University of Chicago Press.

Arabatzis, T. (2017). What's in it for the historian of science? Reflections on the value of philosophy of science for history of science. International Studies in the Philosophy of Science, 31, 69-82.

Baur, E. (1913). Über die Genesis der Kohlenhydrate. Naturwissenschaften, 1(20), 474-477.

Bendall, D. S. (1994). Robert Hill (1899-1991). Biographical Memoirs of Fellows of the Royal Society, 40, $142-170$.

Bird, A. (2014). When is there a group that knows? In J. Lackey (Ed.), Essays in Collective Epistemology (pp. 42-63). Oxford: Oxford University Press.

Boyer-Kassem, T., Mayo-Wilson, C., \& Weisberg, M. (Eds.). (2017). Scientific collaboration and collective knowledge. New essays. Oxford, New York: Oxford University Press.

Bredig, G. (1914a). Katalytische Ameisensäuresynthese unter Druck und ein photochemisch-katalytisches Assimilationsmodell. Chemiker-Zeitung, 38(57), 186-187.

Bredig, G. (1914b). Welche Zwischenprodukte entstehen bei der Assimilation der Kohlensäure durch die Pflanze? Die Umschau, 18, 362-364.

Bredig, G. (1915). Gleichgewicht der Kohlensäurereduktion. Chemiker-Zeitung, 12(72), 72-73.

Chang, H. (2011). Beyond case-studies: History as philosophy. In S. Mauskopf \& T. Schmaltz (Eds.), Integrating history and philosophy of science (pp. 109-124). New York: Springer.

Duysens, L. N. M., \& Amesz, J. (1962). Function and identification of two photochemical systems in photosynthesis. Biochimica et Biophysica Acta, 64, 243-260.

Duysens, L. N. M., Amesz, J., \& Kamp, B. M. (1961). Two photochemical systems in photosynthesis. Nature, 190, 510-511.

Emerson, R., Chalmers, R. V., \& Cederstrand, C. N. (1957). Some factors influencing the long wave limit of photosynthesis. Proceedings of the National Academy of Sciences USA, 43, 133-143.

Emerson, R., \& Chalmers, R. V. (1958). Speculations concerning the function and phylogenetic significance of the accessory pigments of algae. Phycological Society News Bulletin, 11, 51-56.

Erlenmeyer, E. (1877). Das Wasser als Oxydations- und Reductionsmittel. Berichte der Deutschen Chemischen Gesellschaft, 10, 634-635.

Fagan, M. B. (2010). Stems and standards: Social interaction in the search for blood stem cells. Journal of the History of Biology, 43(1), 67-109.

Franck, J. (1949). An interpretation of the contradictory results in measurements of the photosynthetic quantum yields and related phenomena. Archives of Biochemistry, 23, 297-314.

Franck, J. (1951). A critical survey of the physical background of photosynthesis. Annual Review of Plant Physiology, 2, 53-86.

Franck, J. (1958). Remarks on the long-wavelength limits of photosynthesis and chlorophyll fluorescence. Proceedings of the National Academy of Sciences USA, 44, 941-948.

Franck, J., \& Herzfeld, K. F. (1937). An attempted theory of photosynthesis. Journal of Chemical Physics, $5,237-251$.

Franck, J., \& Herzfeld, K. F. (1941). Contribution to a theory of photosynthesis. Journal of Physical Chemistry, 45, 978-1025.

Franck, J. \& Loomis, W. (Eds.) (1949). Photosynthesis in plants: A monograph of the American Society of Plant Physiologists. Iowa: Iowa State College Press.

Franck, J., \& Rosenberg, J. L. (1964). A theory of light utilization in plant photosynthesis. Journal of Theoretical Biology, 7, 276-301.

Goldman, A., \& O'Connor, C. (2019). Social epistemology. The Stanford Encyclopedia of Philosophy (Fall 2019 Edition), Edward N. Zalta (Ed.), URL = <https://plato.stanford.edu/archives/fall2019/entries/ epistemology-social/>.

Govindjee, G. (2004). Robert Emerson, Eugene Rabinowitch: Understanding photosynthesis. In L. Hoddeson (Ed.), No boundaries: University of Illinois Vignettes (pp. 181-194). Chicago: University of Illinois Press.

Govindjee, G., \& Krogmann, D. (2004). Discoveries in oxygenic photosynthesis (1727-2003): A perspective. Photosynthesis Research, 80, 15-27. 
Govindjee, G., \& Rabinowith, E. (1960). Two forms of chlorophyll $a$ in vivo with distinct photochemical functions. Science, 132, 159-160.

Govindjee, G., Shevela, D., \& Björn, L. O. (2017). Evolution of the Z-scheme of photosynthesis. Photosynthesis Research, 135, 5-15.

Graßhoff, G., \& Nickelsen, K. (2011). In pursuit of formaldehyde: Causally explanatory models and falsification. Studies in History and Philosophy of Biological and Biomedical Sciences, 42, 297-305.

Hill, R., \& Bendall, F. (1960). Function of the two cytochrome components in chloroplasts: A working hypothesis. Nature, 186, 136-137.

Holmes, F. L. (2004). Investigative pathways. Patterns and stages in the careers of experimental scientists. New Haven: Yale University Press.

Höxtermann, E. (1992). Fundamental discoveries in the history of photosynthesis research. Photosynthetica, 26, 485-502.

Kitcher, P. (1990). The division of cognitive labour. Journal of Philosophy, 87(1), 5-22.

Kitcher, P. (1993). The advancement of science: Science without legend, objectivity without illusions. Oxford: Oxford University Press.

Keilin, D., \& Hill, R. (1933). Estimation of haematin iron and the oxidation-reduction equivalent of cytochrome c. Proc. Royal Society of London, Series B, 114, 104-109.

Keilin, D. (1966). The history of cell respiration and cytochrome. London: Cambridge University Press.

Knorr-Cetina, K. (1981). Essay on the constructivist and contextual nature of science. Pergamon Press.

Kohler, R. (1982). From medical chemistry to biochemistry: The making of a biomedical discipline. Cambridge: Cambridge University Press.

Kok, B. (1957). Absorption changes induced by the photochemical reaction of photosynthesis. Nature, 179, 583-584.

Kok, B. (1959). Light-induced absorption changes in photosynthetic organisms. II A split-beam difference spectrophotometer. Plant Physiology, 34, 184-192.

Kok, B., \& Hoch, G. (1961). Spectral changes in photosynthesis. In W. D. McElroy \& B. Glass (Eds.), A symposium on light and life (pp. 397-423). Baltimore: The Johns Hopkins Press.

Kuhn, T. (1977). Objectivity, value judgment, and theory choice. In T. Kuhn (Ed.), The essential tension: Selected studies in scientific tradition and change (pp. 320-339). Chicago: University of Chicago Press.

Lemmerich, J. (2007). Aufrecht im Sturm der Zeit: Der Physiker James Franck (1882-1964). Diepholz: Verlag GNT.

McElroy, W. D., \& Glass, B. (Eds.). (1961). A symposium on light and life. Baltimore: The Johns Hopkins Press.

Muldoon, R. (2013). Diversity and the division of cognitive labour. Philosophy Compass, 8(2), 117-125.

Muldoon, R. (2017). Diversity, rationality, and the division of cognitive labour. In T. Boyer-Kassem, et al. (Eds.), Scientific collaboration and collective knowledge (pp. 78-92). Oxford, New York: Oxford University Press.

Myers, J. (1974). Conceptual developments in photosynthesis. Plant Physiology, 54, 420-426.

Nickelsen, K. (2015). Explaining photosynthesis: Modelling biochemical mechanisms 1840-1960. New York et al.: Springer (Series: History, Philosophy and Theory of the Life Sciences, Vol. 8).

Nickelsen, K. (2016). Otto Warburg, die Quanten und die photosynthese. Acta Historica Leopoldina, 65, 37-64. https://doi.org/10.1007/s40656-017-0137-2.

Nickelsen, K. (2017). The organism strikes back: How Chlorella changed photosynthesis research 1920s-1960s. History and Philosophy of the Life Sciences, 39(2:9), 1-29.

Nickelsen, K. (2019). Physiochemical biology and knowledge transfer: The study of the mechanism of photosynthesis between the two world wars. Journal of the History of Biology. https://doi.org/10.1007/ s10739-019-9559-x.

Nickelsen, K., \& Govindjee, G. (2011). The maximum quantum yield controversy. Otto Warburg and the "Midwest-Gang”. Bern: Bern Studies in History and Philosophy of Science.

Rabinowitch, E. (1961). Robert Emerson (1903-1959). Biographical Memoirs of the National Academy of Sciences, 25, 112-131.

Rabinowitch, E., \& Govindjee, G. (1961). Different forms of chlorophyll a in vivo and their photochemical function. In W. D. McElroy \& B. Glass (Eds.), A symposium on light and life (pp. 378-386). Baltimore: The Johns Hopkins Press.

Reinke, J. (1882). Theoretisches zum Assimilationsproblem. Botanische Zeitung, 40(289-297), 305-314.

Stiles, W. (1925). Photosynthesis: The assimilation of carbon by green plants. London: Longmans/ Green.

Solomon, M. (1994). A more social epistemology. In: F. F. Schmitt (Ed.) Socializing epistemology. The social dimensions of knowledge (pp. 111-134). Lanham, Maryld., and London: Rowman \& Littlefield.

Strevens, M. (2003). The role of the priority rule in science. Journal of Philosophy, 100(2), 55-79. 
van Niel, C. B. (1961). Introductory Comments. In W. D. McElroy \& B. Glass (Eds.), A symposium on light and life (pp. 315-316). Baltimore: The Johns Hopkins Press.

van Niel, C. B. (1967). The education of a microbiologist: Some reflections. Annual Review of Microbiology, 21, 1-30.

von Baeyer, A. (1871). Über die Wasserentziehung und ihre Bedeutung für das Pflanzenleben und die Gährung. Berichte der Deutschen Chemischen Gesellschaft, 3, 63-75.

von Liebig, J. (1843). Die Wechselwirthschaft. Annalen der Chemie und Pharmazie, 46, 58-97.

Weisberg, M., \& Muldoon, R. (2009). Epistemic landscapes and the division of cognitive labor. Philosophy of Science, 76(2), 225-252.

Willstätter, R., \& Stoll, A. (1913). Untersuchungen über Chlorophyll. Berlin: Springer.

Willstätter, R., \& Stoll, A. (1918). Untersuchungen über die Assimilation der Kohlensäure. Berlin: Springer.

Witt, H. T. (1960). Untersuchungen der Photosynthese bei Anregung mit Blitzlicht. In A. Pirson (Ed.), Handbuch der Pflanzenphysiologie (pp. 634-674). Berlin: Springer.

Witt, H. T., Müller, A., \& Rumberg, B. (1961a). Experimental evidence for the mechanism of photosynthesis. Nature, 191, 194-195.

Witt, H. T., Müller, A., \& Rumberg, B. (1961b). Oxidized cytochrome and chlorophyll in photosynthesis. Nature, 192, 967-969.

Witt, H. T. (1991). Functional mechanism of water splitting photosynthesis. Photosynthesis Research, 29, $55-77$.

Wray, K. B. (2002). The epistemic significance of collaborative research. Philosophy of Science, 69(1), $150-168$.

Zallen, D. (1993). The "light" organism for the job: Green algae and photosynthesis research. Journal of the History of Biology, 26, 269-279.

Publisher's Note Springer Nature remains neutral with regard to jurisdictional claims in published maps and institutional affiliations. 